\title{
Role of Platelet Rich Plasma (PRP) injection in treatment of rotator cuff tear
}

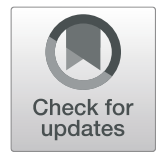

\author{
Nermin Hassan El Gharbawy and Hossam Salaheldin Labib * (1D
}

\begin{abstract}
Background: One of the commonest causes of shoulder pain and disability is partial thickness tear of the rotator cuff. Platelet-rich plasma (PRP) therapy is a volume of the plasma fraction of autologous blood that has platelet concentration above the baseline. It is theorized that PRP may help stimulate the development of normalappearing histologic tissue characteristics at the repair site and improve clinical outcomes. Our purpose is to assess the efficacy of PRP therapy in treatment of rotator cuff tear. This prospective single-center study involved 30 patients (aged $31.7 \pm 7.7$ years, $63.3 \%$ males) complaining of symptomatic rotator cuff tear. Platelet-rich plasma (PRP) injection was done to all patients. Before and after injection of PRP, scoring was done using visual analog score, Shoulder Pain and Disability Index (SPADI), and musculoskeletal ultrasound scoring of the tear. Reassessment was done 4 weeks after the injections.

Results: The pre-injection VAS pain score was $7.1 \pm 0.99$ after injection, and it became $3.7 \pm 1.09$. Also, SPADI score decreased from $78.03 \pm 8.25$ pre-injection to $42.1 \pm 13.97$ post-injection. There was a highly statistically significant difference in VAS pain score and SPADI score before and after PRP injection $(p<0.001)$. There was highly statistically significant positive correlation between the improvement of US grading score change and the improvement of VAS score change, and between it and SPADI improvement change $(r=0.695, p<0.001$ and $r=$ $0.693, p<0.001$, respectively). There was a highly statistically significant difference between US grading score before and after PRP injection $(p<0.001)$.

Conclusion: PRP can be considered an effective method for treatment of rotator cuff tear and less invasive compared to surgical treatment. It improves the pain, shoulder function, and tear size.
\end{abstract}

Keywords: Platelet-rich plasma, Muscle tear, Rotator cuff, Musculoskeletal ultrasound

\section{Background}

One of the commonest causes of shoulder pain and disability is partial thickness tear of the rotator cuff (PTRCTs). Surgical treatment of the tear improves the patient outcome, but there is a risk of post-surgical infections, delayed healing, shoulder stiffness, and injury to other tendons [1].

Musculoskeletal ultrasound (MSUS) is a diagnostic tool that can be used to detect and confirm partial or full-thickness rotator cuff tear [2].

\footnotetext{
* Correspondence: dr.sam789@yahoo.com

Rheumatology, Physical Medicine and Rehabilitation Department, Ain Shams University, Building 180, 47th Street, Fifth District, Fifth settlement, New Cairo PO 11835, Egypt
}

There are several studies about using blood or its products to decrease the pain and improve the healing process tendon tears [3]. Platelet-rich plasma (PRP) triggers growth factor (PDC vascular endothelial growth factor (VEGF) that helps multiplying of endothelial cell and transforming growth actor (TGF) which enhances collagen synthesis and [4]. The aim of this study was to assess the efficacy of PRP

\section{Methods}

This is a prospective single-center study included $30 \mathrm{pa}$ tients recruited from the outpatient clinics of Physical 
Medicine, Rheumatology and Rehabilitation department from 2017 to 2018.

This study included all patients aged $>18$ and $<45$ years who had shoulder pain with overhead activity and pain score $\geq 5$ on visual analog scale (VAS) in addition to painful arc or impingement signs and were diagnosed by MSUS to have partial rotator cuff tear.

The exclusion criteria were presence of other causes of shoulder pain and dysfunction as fracture, bone disease, gouty arthritis, rheumatoid arthritis, systemic diseases, such as hepatitis, diabetes mellitus, or blood diseases, referred pain from cervical spine, history of steroid injection within 6 weeks and/or non-steroidal use within the last 2 weeks, hemoglobin level less than $11 \mathrm{gm} / \mathrm{dl}$ or platelet less than 150,000 IU, and pregnancy.

\section{Study design}

This study was approved by the research ethical committee and an informed written consent was obtained from all patients prior to their inclusion in the study.

A detailed medical history and clinical examination were done for all study population.

Active and passive ranges of motion of the shoulder were assessed using goniometer. Shoulder pain was assessed by visual analog scale (VAS). Shoulder function was assessed by Shoulder Pain and Disability Index (SPADI) [5], which has two items the first is pain scale consists of four grades; each of them was graded from 0 to $10(0=$ no pain while $10=\max -$ imum pain), and then we calculate the total pain score $=\ldots . . / 50 \times 100=\ldots \ldots . . \%$.

The second item is disability scale which consists of eight items; each of them was graded from 0 to $10(0=$ no difficulty while $10=$ marked difficulty), and then we calculate the total disability score $=\ldots . . / 80 \times 100=\ldots . . \%$ followed by calculating the total SPADI $=\ldots . . / 130 \times$ $100=\ldots . . . \%$.

In addition, other tests were performed: complete blood profile (Coulter counter), erythrocyte sedimentation rate (ESR) (Westergren method), $2 \mathrm{~h}$ post-prandial blood sugar level (glucose oxidase method), and serum uric acid (uricase method).

\section{High-resolution MSUS assessment of the shoulder}

It was performed using a high-frequency (0-12 MHZ) linear transducer (LOGIQ 500 pro series, GE Medical Systems, USA). The examination started while the patient was setting for proper visualization of the shoulder. The transverse and longitudinal scans were applied to the shoulder for assessment of rotator cuff tendons.
Rotator cuff findings were described as follows: normal, tendinosis, tendinitis, partial tear, or full thickness tear. Ultrasound grading of rotator cuff tendon [6] in which grade 0: normal (hyperechoic, fibrillary echotexture), grade 1: mild tendinosis (heterogeneous echo texture with ill-defined hyperechoic regions), grade 2: severe tendinosis (diffuse abnormal hypoechogenicity without tendon volume loss), grade 3: intrasubstance abnormality (focal, well-defined, hypoechoic, or anechoic area not extending to either the bursal or articular tendon surface), grade 4: partial thickness tendon tear (focal, well-defined, hypoechoic, or anechoic area extending to either the bursal or articular surface of the tendon), grade 5 : focal full-thickness tendon tear (focal, well-defined, hypoechoic, or anechoic area extending to either the bursal or articular tendon surface with tendon volume loss), grade 6: full-thickness tear (nonvisualization of tendon with retraction).

\section{PRP technique}

PRP was prepared using a platelet concentration system (centerion 2006 England). Initially, the patient's blood was collected under aseptic precautions. Vein puncture was done for collection of $45 \mathrm{ml}$, then mixed with $6 \mathrm{ml}$ citrate in a special-designed disposable tubes (falcon tubes) for double centrifugation; first, for $15 \mathrm{~min}$ at $1600 \mathrm{rpm}$ to separate RBCs from the plasma, and second, the plasma was separated and centrifuged for $10 \mathrm{~min}$ at $3200 \mathrm{rpm}$ to separate platelet-rich plasma from platelet-poor plasma, and $6 \mathrm{ml}$ of PRP was obtained. One milliliter of PRP was collected for blood counting to establish the platelet concentration (at least double the serum concentration), and the remaining $5 \mathrm{ml}$ without any buffering or activating agent was injected under complete aseptic condition and under US guidance into the partial tear of the tendon or around it. After injection, patients were instructed to rest from overhead activity and rotatory movements of the shoulder for 2 days after the injection. Acetaminophen and compression were allowed if needed for post-injection pain control. After 2 days, a 3-week exercise program started which involved passive range of motion and Codman exercises. When the pain subsided and movement was tolerated, stretching the posterior capsule and pectoral muscles, and light resistive exercise of the rotator cuff and scapular muscles were added to the program. The patients moved to home-based program focusing on isotonic strengthening and stretching exercises for further 3 weeks. The total duration of exercise programs were 6 weeks.

\section{Statistical analysis}

All data were revised and statistically analyzed using IBM SPSS software package version 20. Descriptive statistics was performed for all variables in the study. 
Table 1 Demographic data of patients

\begin{tabular}{lllll}
\hline & & N & & $\%$ \\
\hline Sex & Male & 19 & & 63.33 \\
& Female & 11 & & 36.67 \\
Age (years) & Range & 19 & - & 45 \\
& Mean \pm SD & 31.767 & \pm & 7.682 \\
Disease duration (weeks) & Range & 2 & - & 50 \\
& Mean \pm SD & 11.400 & \pm & 13.415 \\
\hline
\end{tabular}

For categorical variables, absolute counts and percentages were generated. For quantitative variables, the range, mean, SD, and SEM were calculated. Comparison of categorical data was done using the w2-test. Quantitative data were tested either using the Student $t$ test (for parametric data) or the Mann-Whitney $U$ test (for non-parametric significance). The correlation was calculated using the Pearson correlation coefficient $(r)$ to determine the relationship among different variables. A $p$ value was considered significant if it was $<0.05$. Data were graphically represented using the HGW program (USA).

\section{Results}

This single-center prospective study was conducted on 30 patients with symptoms and signs suggestive of rotator cuff tear. Patient's ages ranged from 19 to 45 with mean $\pm \mathrm{SD}(31.7 \pm 7.7)$ years. They were 19 males (63.3\%) and 11 females (36.7\%), and disease duration ranged from 2 to 50 weeks with mean \pm SD (11.400 \pm 13.415) weeks (Table 1 )

We found that according to ultra-sonogram grading score, 18 patients $(60 \%)$ were grade 3,8 patients
Table 2 Comparison between US grading score before and after PRP injection

\begin{tabular}{|c|c|c|c|c|c|c|}
\hline \multirow{2}{*}{$\begin{array}{l}\text { US } \\
\text { grading } \\
\text { of tear }\end{array}$} & \multicolumn{2}{|c|}{$\underline{\text { Before injection }}$} & \multicolumn{2}{|c|}{ After injection } & \multicolumn{2}{|c|}{ Chi-square } \\
\hline & $N$ & $\%$ & $N$ & $\%$ & $x^{2}$ & $p$ value \\
\hline G1 & 0 & 0.00 & 16 & 53.33 & 40.800 & $<0.001^{*}$ \\
\hline G2 & 4 & 13.33 & 12 & 40.00 & & \\
\hline G3 & 18 & 60.00 & 2 & 6.67 & & \\
\hline G4 & 8 & 26.67 & 0 & 0.00 & & \\
\hline Total & 30 & 100.00 & 30 & 100.00 & & \\
\hline
\end{tabular}

(26\%) were grade 4 , and only 4 patients (13\%) were grade 2 .

There was a highly statistically significant difference between US grading score before and after PRP injection $(p<0.001)$ (Table 2, Figs. 1 and 2).

We found that the pre-injection VAS pain score with mean \pm SD was $7.1 \pm 0.99$, and after injection, it became $3.7 \pm 1.09$. Also, the SPADI score decreased from initial mean $\pm \mathrm{SD}(78.03 \pm 8.25)$ before injection to mean \pm SD $(42.1 \pm 13.97)$ after injection. There was a highly statistically significant difference in VAS pain score and SPADI score before and after PRP injection $(p<0.001)$ (Table 3$)$.

There were highly statistically significant positive correlation between the improvement of US grading score change and the improvement of VAS score change, SPADI improvement change $(p<0.001)$ (Table 4 , Figs. 3 and 4$)$.

There were highly statistically significant positive correlation between the improvement of VAS score change and SPADI score improvement change $(p<0.001)$ (Table 4).

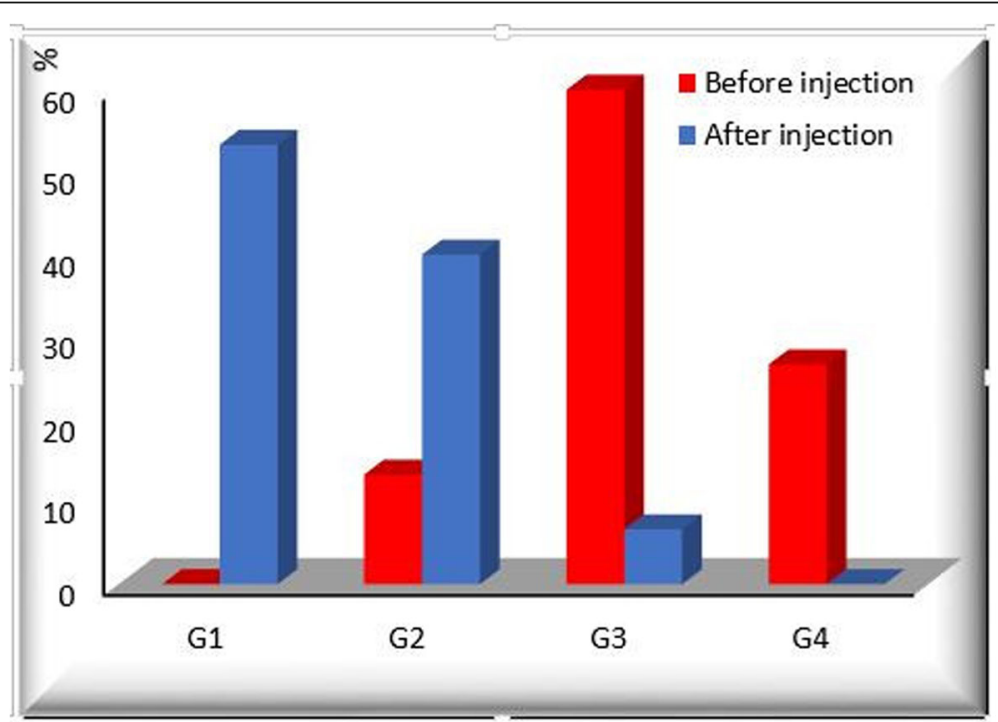

Fig. 1 US grading before and after injection 


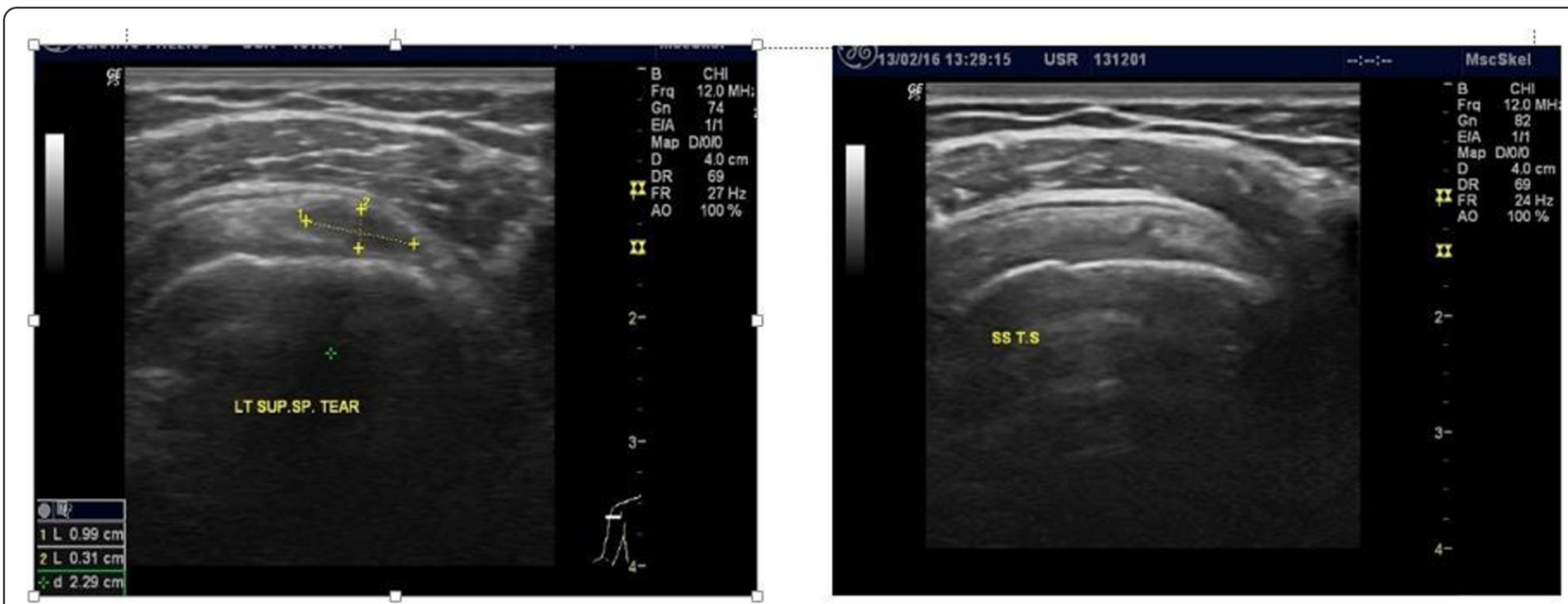

Fig. 2 Ultrasound views on left supraspinatus muscle in patient no. 5. Left panel revealed a G3 tear measured $0.99 \times 0.31 \mathrm{~cm}$ (yellow lines). Before PRP injection while right panel revealed improvement in tear to Gl after PRP injection in the same patient

\section{Discussion}

One of the commonest causes of shoulder pain and disability is the partial thickness tear of the rotator cuff [7]; it ranges from 13 to 32\% [8]. One-third of the silent rotator cuff tears will become symptomatic throughout the following years. The prevalence of degenerative rotator cuff tears in the population will increase as the number of elderly grows. Most studies on PTRCTs have explained surgical techniques and surgical outcomes; however, few of them have discussed the non-operative modalities including PRP injection $[9,10]$.

The PRP injection was first described by a research group in Spain for maxillofacial and plastic surgery in 1999 [11]. Recent studies have assessed the biologic enhancement of the healing process and PRP is able to produce growth factors, collagen, and probably an increase in the number of stem cells, which consequently enhance healing by delivering high concentrations of alpha-granules containing biologically active moieties such as transforming growth factor- $\beta$ and vascular endothelial growth factor to the areas of soft tissue damage [12-14]. PRP has been shown to be effective and safe. It can be applied either as a non-operative method of treatment or intra-operative [15]. In this study, we aimed to assess the efficacy of local injection of autologous PRP on pain and function of the patients with PTRC Ts. There was a highly statistically significant difference in the improvement of VAS pain score, SPADI score, and US grading score. The mean pain score decreased from $7.1 \pm 0.99$ to $3.7 \pm 1.09$ following a single PRP injection; the recent studies concluded that a reduction of two points on a $0-10$ VAS scale corresponded to a significant clinical difference across a variety of pain conditions [16], and these results therefore suggest a strong clinical effect. Improved pain scores were accompanied by improved functional and US outcomes, suggesting that healing occurred at the tissue level. Improvements in pain and function outcomes are consistent with those reported in other studies as Michael et al. 2013 and Sengodan et. al. 2017 [17, 18].

This study showed a significant improvement in postinjection SPDAI score compared to the pre-injection score. This is accompanied by adequate improvement in shoulder function with increase shoulder range of motion. These results agreed with Wesner et al. [19] and Byun et al. [20] who found that patients ROM, VAS, and functional score significantly improved at follow-up after PRP injection. In another study, PRP injection was effective and better than corticosteroid injection or

Table 3 Comparison between VAS score and SPADI before and after injection

\begin{tabular}{|c|c|c|c|c|c|c|c|}
\hline & & \multirow[b]{2}{*}{ Before injection } & \multirow[b]{2}{*}{ After injection } & \multicolumn{2}{|c|}{ Differences } & \multicolumn{2}{|c|}{ Paired test } \\
\hline & & & & Mean & SD & $t$ & $p$ value \\
\hline \multirow[t]{2}{*}{ Pain score (VAS) } & Range & $5-9$ & $2-6$ & 3.400 & 1.163 & 16.018 & $<0.001^{*}$ \\
\hline & Mean \pm SD & $7.1 \pm 0.99$ & $3.70 \pm 1.09$ & & & & \\
\hline \multirow[t]{2}{*}{ SPADI \% } & Range & $60-90$ & $20-75$ & 35.933 & 15.125 & 13.013 & $<0.001^{*}$ \\
\hline & Mean \pm SD & $78.033 \pm 8.252$ & $42.1 \pm 13.97$ & & & & \\
\hline
\end{tabular}


Table 4 Correlations between US grading changes with other variables and correlation between VAS score change and SPADI score change

\begin{tabular}{|c|c|c|c|c|}
\hline \multicolumn{5}{|l|}{ Correlations } \\
\hline & \multicolumn{2}{|c|}{ US grading change } & \multicolumn{2}{|c|}{ Pain score (VAS) change } \\
\hline & $\bar{r}$ & $p$ value & $\bar{r}$ & $p$ value \\
\hline Pain score (VAS) change & 0.695 & $<0.001^{*}$ & & \\
\hline SPADI \% change & 0.693 & $<0.001^{*}$ & 0.802 & $<0.001^{*}$ \\
\hline
\end{tabular}

ultrasonic therapy in the treatment of periarthritis of the shoulder by improving ROM, pain, and disability [21]. Also, PRP injection was found to be effective in the patients who failed to respond to the other conservative treatments [22].

The rapid recovery of shoulder ROM and the improvement of the rotator cuff function because of PRP improve tendon-bone healing and potentially reduce the incidence of subsequent tendon retears and also reduce pain which allows for a more rapid recovery $[23,24]$.

According to use of diagnostic US to evaluate the patients, there was highly statistically significant difference between US grading score before and after PRP injection, also there was highly statistically significant positive correlation between the improvement of US grading score change and the improvement of VAS score change, SPADI improvement change. This comes in accordance with Mathieu et al. 2010 [25] who reported that US is a reliable diagnostic tool that obviates the need for further imaging in most cases. Their study established that US and MRI showed comparably high sensitivity, diagnostic accuracy, and positive predictive value in detecting full or partial thickness rotator cuff tears; however, US was more sensitive than MRI in detection of partial-thickness tear of the rotator cuff .

PRP is an evolving treatment modality gaining momentum in the rehabilitation and sports medicine applications. In vivo studies suggest that biologically active substances and concentrated growth factors within PRP can initiate a healing cascade by the action of the elevated cytokines concentrations released during platelet degranulation, which stimulates the capillary regeneration within the area of tendon tear [26]. The mechanism of tendon regeneration and healing may be responsible for the clinical and structural improvement seen in this study.

Physical therapy is usually the first line of the treatment for symptomatic PTRCTs, although the optimal protocol is not well established and significant heterogeneity exists between the rehabilitation programs $[27,28]$. PRP has provided additional benefits compared to physical therapy alone. The outcomes of surgery for PTRCTs compared to non-operative management are not definitive; most of studies suggested that there are no significant differences in outcome between operative and non-operative treatment for PTRCTs [19]. PRP provide a minimally invasive non-operative treatment for PTRCTs and can be considered a less expensive alternative to surgery with reduced potential for operative side effects and adverse events.

\section{$r=0.695 \quad P$-value $<0.001^{*}$}

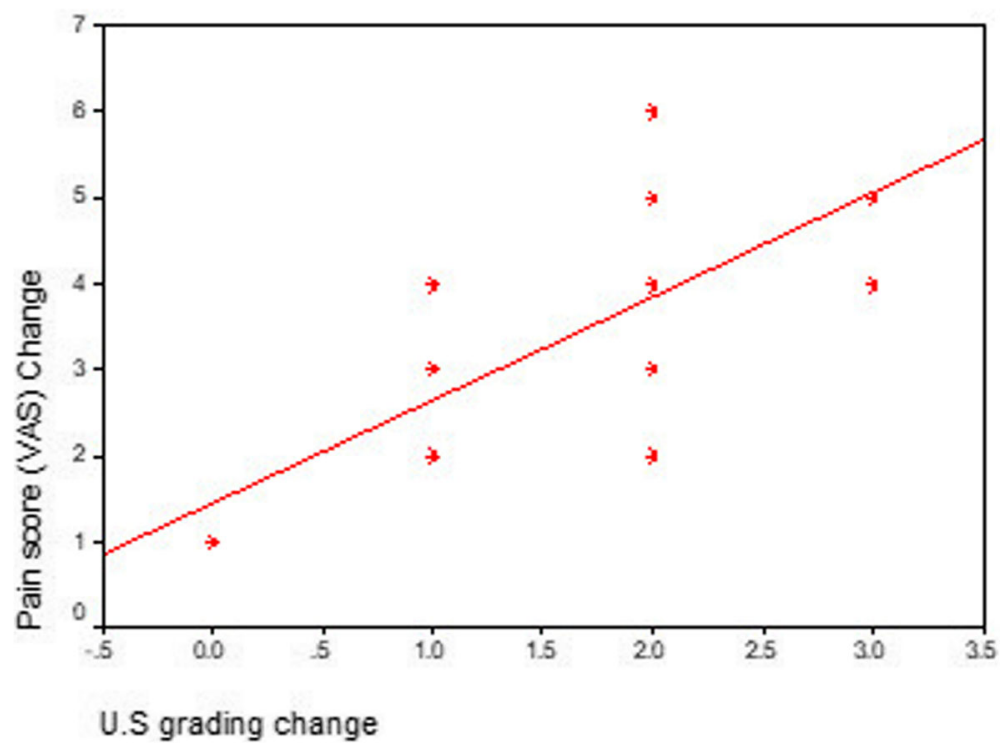

Fig. 3 Correlation between US grading change and VAS change 


\section{$r=0.693 \quad$ P-value $<0.001^{*}$}

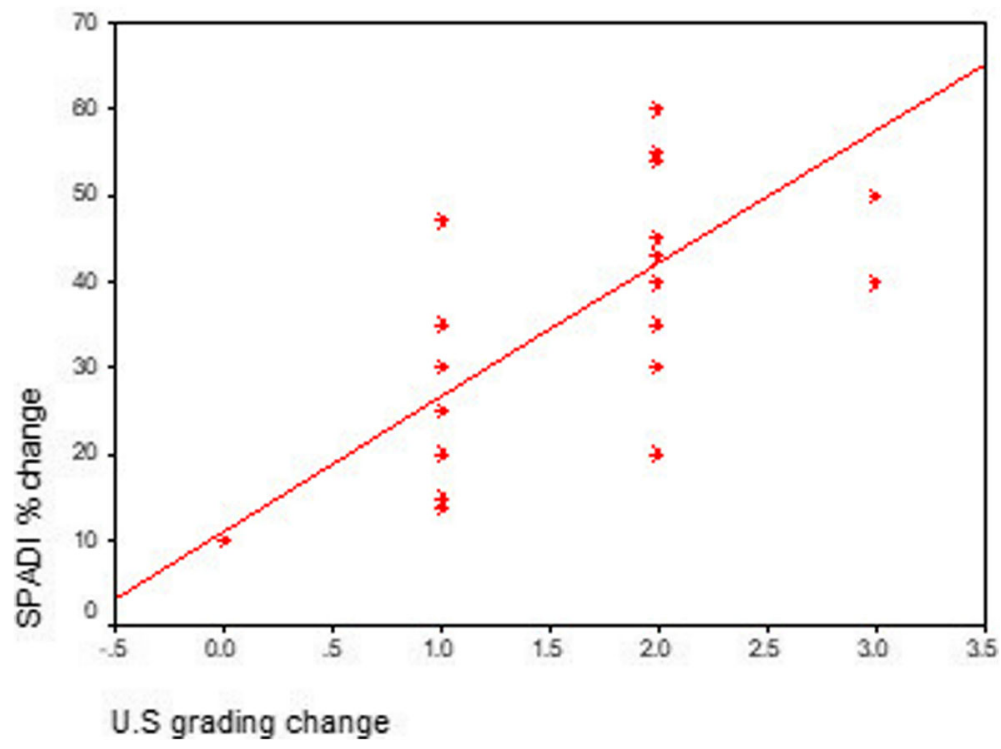

Fig. 4 Correlation between US grading change and SPADI change

\section{Study limitations}

The study had a small sample size and lack of a control group for comparison. It is therefore impossible to know the extent to which these subjects would have improved without PRP injection. The primary $0-10$ point VAS outcome measure is not validated for RCT; however, VAS scores are an accepted measure of pain and have been used as primary outcomes in studies of chronic pain [29] and injection therapy specifically [30]. The study also was limited by lack US follow-up beyond the 4-week period. Although US imaging during this short follow-up period demonstrated the improvements in the most of patients, tendon healing models suggest that tendon remodeling continues for up to 1 year or more following acute injury [31].

Determination of clinical utility of PRP for RCT will require assessment in a larger randomized controlled setting, ideally in comparison to current conventional therapy. Consideration should be given to the use of ultrasound follow-up to assess the extent of tissue healing after 3, 6, and 12 months.

\section{Conclusion}

PRP can be considered an effective method for treatment of rotator cuff tear and less invasive compared to surgical treatment. It improves the pain, shoulder function, and tear size.

\section{Abbreviations}

MRI: Magnetic resonance imaging; MSUS: Musculoskeletal ultrasound; ESR: Erythrocyte sedimentation rate; G: Grade; PTRCTs: Partial thickness rotator cuff tear; PDGF: Platelet derived growth factor; PRP: Platelet-rich plasma; SPADI: Shoulder Pain and Disability Index; TGF: Transforming growth factor; US: Ultrasound; VAS: Visual analog scale; VEGF: Vascular endothelial growth factor

\section{Acknowledgements}

Not applicable.

\section{Authors' contributions}

The authors listed below have contributed significantly to the submitted work: NHE gave idea and collected the patients' data and analyze them. HSL put study design and followed the patients after injection. Both wrote the paper with revision. They all read and approved the final version of the manuscript.

\section{Funding}

This study had no funding from any resource.

Availability of data and materials

They are available from the corresponding author on reasonable request.

\section{Ethics approval and consent to participate}

This study was approved by the research ethical committee (REC) of Faculty of Medicine, Ain shams University, 10 August 2018, and an informed written consent was obtained from all patients prior to their inclusion in the study.

\section{Consent for publication}

All patients included in this research gave written informed consent to publish the data contained within this study.

\section{Competing interests}

All authors declare that they have no competing interests.

Received: 22 June 2020 Accepted: 2 July 2020

Published online: 15 December 2020

\section{References}

1. Cheung EV, Silverio L, Sperling JW (2010) Strategies in biologic augmentation of rotator cuff repair: A review. Clin Orthop Relat Res 468: 1476-1484 
2. Vlychou M, Dailiana Z, Fotiadou A, Papanagiotou M, Fezoulidis IV, Malizos K (2009) Symptomatic partial rotator cuff tears: diagnostic performance of ultrasound and magnetic resonance imaging with surgical correlation. Acta Radiol 50:101-105

3. Chahal J, Van Thiel GS, Mall N, Heard W, Bach BR, Cole BJ et al (2012) The role of platelet-rich plasma in arthroscopic rotator cuff repair: A systematic review with quantitative synthesis. Arthroscopy 28:1718-1727

4. Sanchez M, Anitua E, Orive G, Mujika I, Andia I (2009): Platelet-rich therapies in the treatment of orthopaedic sports injuries. Sports Med 2009; 35:1-10.

5. Roach KE, Budiman-Mak E, Songsiridej N, Lertratanakul Y (1991)

Development of a shoulder pain and disability index. Arthritis Care Res 4(4): 143-149

6. Collinger JL, Fullerton B, Impink BG, Koontz AM, Boninger ML (2010) Validation of greyscale-based quantitative ultrasound in manual wheelchair users: relationship to established clinical measures of shoulder pathology. Am J Phys Med Rehabil 89(5):390-400

7. Barber FA, Hrnack SA, Snyder SJ, Hapa O (2011) Rotator cuff repair healing influenced by platelet-rich plasma construct augmentation. Arthroscopy 27(8):1029-1035

8. Maniscalco P, Gambera D, Lunati A, Vox G, Fossombroni V, Beretta R (2008) The "Cascade" membrane: a new PRP device for tendon ruptures. Description and case report on rotator cuff tendon. Acta Biomed 79(3):223226

9. Fu CJ, Sun JB, Bi ZG, Wang XM, Yang CL (2017) : Evaluation of platelet-rich plasma and fibrin matrix to assist in healing and repair of rotator cuff injuries: a systematic review and meta-analysis. Clin Rehabil 2017; 31(2):158172.

10. Jo CH, Shin JS, Shin WH, Lee SY, Yoon KS, Shin S (2015) Platelet-rich plasma for arthroscopic repair of medium to large rotator cuff tears: a randomized controlled trial. Am J Sports Med 43(9):2102-2110

11. Anitua $E$ (1999) Plasma rich in growth factors: preliminary results of use in the preparation of future sites for implants. Int J Oral Maxillofac Implants 14(4):529-535

12. Sheth U, Simunovic N, Klein G, Fu F, Einhorn TA, Schemitsch E (2012) Efficacy of autologous platelet-rich plasma use for orthopaedic indications: a meta-analysis. J Bone Joint Surg Am 94(4):298-307

13. Nourissat G, Mainard D, Kelberine F (2013) Current concept for the use of PRP in arthroscopic surgery. Orthop Traumatol Surg Res 99(8 Suppl):S407S410

14. Nixon AJ, Watts AE, Schnabel LV (2012) Cell- and gene-based approaches to tendon regeneration. J Shoulder Elb Surg 21(2):278-294

15. Cheung EV, Silverio L, Yao J (2010) Delivered growth factor therapy to improve healing after rotator cuff repair. Stem Cells Cloning 3(1):135-144

16. Farrar JT, Young JP, LaMoreaux $L$ (2001) Clinical importance of changes in chronic pain intensity measured on an 11-point numerical rating scale. Pain. 94:149-158

17. Michael S, David R, Edward S, Patrick D, Perry P, Gennie A et al (2013) Effectiveness of platelet-rich plasma injection for rotator cuff tendinopathy: a prospective open-label study. Global Adv Health Med 2(2):26-31

18. Sengodan VC, Kurian S, Ramasamy R (2017) Treatment of Partial Rotator Cuff Tear with Ultrasound-guided Platelet-rich Plasma. J Clin Imaging Sci 7:32

19. Wesner M, Defreitas T, Bredy H, Pothier L, Qin Z, McKillop AB et al (2016) A pilot study evaluating the effectiveness of platelet-rich plasma therapy for treating degenerative tendinopathies: a randomized control trial with synchronous observational cohort. PLoS One 11(2):e0147842

20. Byun SD, Hong YH, Hong SK, Song JW, Woo SB, Noh JH et al (2014) Effects of repeated steroid injection at subacromial bursa with different interval. Ann Rehabil Med 38(6):805-811

21. Kothari SY, Srikumar V, Singh N (2017) Comparative efficacy of platelet rich plasma injection, corticosteroid injection and ultrasonic therapy in the treatment of per arthritis shoulder. J Clin Diagn Res 11(5):RC15-RC18

22. Tahririan MA, Moezi M, Motififard M, Nemati M, Nemati A (2016) Ultrasound guided platelet-rich plasma injection for the treatment of rotator cuff tendinopathy. Adv Biomed Res 5:200

23. Ebert JR, Wang A, Smith A, Nairn R, Breidahl W, Zheng MH et al (2017) A midterm evaluation of postoperative platelet-rich plasma injections on arthroscopic supraspinatus repair: a randomized controlled trial. Am J Sports Med 45(13):2965-2974

24. D'Ambrosi R, Palumbo F, Paronzini A, Ragone V, Facchini RM (2016) Plateletrich plasma supplementation in arthroscopic repair of full-thickness rotator cuff tears: a randomized clinical trial. Musculoskelet Surg 100(Suppl1):25-32
25. Matthieu J, Spaargaren G-J, van Loon T, Maarten C, Lambertus A, Gerrit J (2010) Detection of rotator cuff tears: the value of MRI following ultrasound. Eur Radiol 20:450-457

26. Everts PA, Knape JTA, Weibrich GW et al (2006) Platelet-rich plasma and platelet gel: A review. J Extra Corpor Technol 38:174-187

27. Shams A, El-Sayed M, Gamal O, Ewes W (2016) Subacromial injection of autologous platelet-rich plasma versus corticosteroid for the treatment of symptomatic partial rotator cuff tears. Eur J Orthop Surg Traumatol 26(8): 837-842

28. Zhang J, Wang JH (2014) PRP treatment effects on degenerative tendinopathy-an in vitro model study. Muscles Ligaments Tendons J 4:1017

29. Von Wehren L, Blanke F, Todorov A, Heisterbach P, Sailer J, Majewski M (2016) The effect of subacromial injections of autologous conditioned plasma versuscortisone for the treatment of symptomatic partial rotator cuff tears. Knee Surg Sports Traumatol Arthrosc 24(12):3787-3792

30. Ryan M, Wong AD, Taunton J (2010) Favorable outcomes after sonographically guided intra-tendinous injection of hyperosmolar dextrose for chronic insertional and midportion achilles tendinosis. AJR Am J Roentgenol 194:1047-1053

31. Bagge J, Lorentzon $\mathrm{R}$, Alfredson $\mathrm{H}$ et al (2009) Unexpected presence of neurotropins NGF and BDNF and neurotrophin receptor p75 in the tendon cells of human Achilles tendon. Histopathol. 24:839-848

\section{Publisher's Note}

Springer Nature remains neutral with regard to jurisdictional claims in published maps and institutional affiliations.

\section{Submit your manuscript to a SpringerOpen ${ }^{\circ}$ journal and benefit from:}

- Convenient online submission

- Rigorous peer review

- Open access: articles freely available online

- High visibility within the field

- Retaining the copyright to your article

Submit your next manuscript at $\boldsymbol{\nabla}$ springeropen.com 